\title{
Seismic hazard assessment in Continental Asia
}

\author{
Peizhen Zhang \\ Institute of Geology, State Seismological Bureau, Beijing, P.R. China
}

\begin{abstract}
This contribution reviews the status of seismic hazard assessment in Continental Asia; the surveyed region includes China, Nepal, Northern India and Pakistan, Mongolia and parts of the former USSR territory. The area is characterized by intense and catastrophic seismic activity; about $80 \%$ of worldwide continental activity takes places in this area.
\end{abstract}

\section{Introduction}

Continental Asia is region with a high level of seismic hazard. Statistics of global earthquakes from 1900 to 1985 indicate that 13 percent of shallow-depth earthquakes $(\mathrm{Ms} \geq 7$ ) occurred in the interior of continents (intraplate). Eighty percent of these continental earthquakes occurred in Continental Asia (Feng Hao, 1989). In China, for example, there have been 9 great earthquakes $(\mathrm{Ms} \geq 8$ ) and 80 large earthquakes $(8>\mathrm{Ms} \geq 7)$ between 1900 and 1985, which account for more than $1 / 3$ of the total amount of earthquakes that have occurred in Continental Asia between 1900 and 1986 (fig. 1).

Although only 13 percent of all global earthquakes occur in the interior of continents, the resulting social and economic impact is no less than that from the other 87 percent earthquakes occurred along the plate boundaries which commonly occur offshore as subduction zone, middle ocean ridge, and trasform fault earthquakes. The continental earthquakes cause widespread loss of life, property damage, and social and economic disruption. For example, the nine $\mathrm{Ms}>7$ earthquakes that successively struck China from 1966 to 1978 (Ma Zongjin et al., 1989) are a tragic example of seismic disasters in Continental Asia. These nine earthquakes occurred in densely populated areas and caused approximately 300000 casualties and more than 2 billion US dollars in economic damage. The tragedy caused by the 1976 Tangshan earthquakes is still fresh in our memory even 16 years after the event. Major earthquakes in Iran, Turkey, regions of the former USSR, India, Burma, and other countries in Continental Asia also caused great loss of life and economic disaster. Thus. seismic hazards pose a major threat to the social and economic development of most countries in Continental Asia, most of which are developing nations.

In this review, I will first describe the nature of seismic hazards in Continental Asia, then review status of seismic hazard assessments, and finally discuss problems and future directions in seismic hazard assessment in Continental Asia.

\section{Nature of seismic hazard in Continental Asia}

Unlike earthquakes that occur along plate boundaries, continental earthquakes are widely distributed over large regions (fig. 2) and typically have shallow focal depths, in the range of 10 to $25 \mathrm{~km}$ beneath the surface (fig. 3). Major continental earthquakes usually occur 


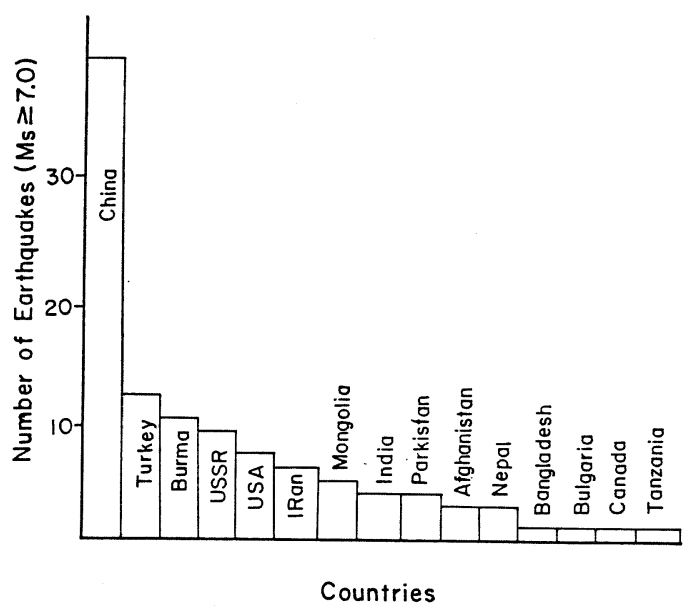

Fig. 1. Bar diagram showing numbers of shallow-depth continental earthquakes distributed in different countries.

along seismically active faults, which individually have very long recurrence intervals (in the range of several thousand years). However, the recurrence interval for major earthquakes in a particular region is much shorter (a few decades). Although our understanding of the spatial and temporal behavior of continental earthquakes is still at a very preliminary level, general characteristics of continental earthquakes are elucidated below.

\subsection{Distribution of continental earthquakes}

Late Quaternary deformation of Continental Asia is distributed over a vast region, and includes a full spectrum of deformational styles and structural orientations. Much, if not all, of the deformation can be attributed to the collision and subsequent penetration of the Indian plate with respect to Eurasia (for example, Molnar and Tapponnier, 1975, 1978; Tapponnier and Molnar, 1977; 1979). The occurrence and distribution of strong earthquakes are the manifestation and result of these widespread and varied styles of deformation. The locations of earthquakes, especially large earthquakes is not uniformly and randomly distributed - rather they cluster in several belts and regions of prominent late Quaternary tectonic activity (fig. 2).

Since the present boundary between the Indian and Eurasian plates is approximately along the Himalaya front thrust fault zone, south of the Tibetan Plateau, and the Indian plate continues to move north under the Eurasian plate (Lyon-Caen and Molnar, 1985), strong compression and major thrust-faulting earthquakes characterize the modern seismicity along the arcuate belt that extends from Burma, Bangladesh, India, Pakistan, Iran, and west to Turkey and Greece. This long zone of compressional tectonics is commonly referred to as the Himalaya seismic belt. Seismic hazards in this seismic belt will be reviewed by Gupta (this volume).

Tibetan Plateau. There have been more than $30 \mathrm{Ms} \geq 7$ earthquakes in the interior of the Tibetan Plateau, and five of them are of magnitude 8 or larger. Fault plane solutions of the earthquakes show normal and strike-slip mechanism with consistent $\mathrm{T}$-axes oriented between east - west and northwest - southeast (Chen and Molnar, 1983; Molnar and Lyon-Caen, 1989). Active fault studies in the central Tibet Plateau also reveal normal and strike-slip faulting as ongoing tectonic processes (Armijo et al., 1986). Since this region is sparsely populated, these earthquakes are considered a lesser risk than those in the densely populated areas of Eastern and Southern China.

Northern and eastern margin of the Tibetan Plateau. Crustal shortening is the predominant late Cenozoic tectonic process is this area as the Tibetan Plateau is apparently being overthrust to the north and to the east. Active reverse faults and reverse faults with a strong strike-slip component are predominant in this belt of deformation. Fault plane solutions of earthquakes also show thrust faulting with strike-slip component (Molnar and Lyon-Caen, 1989). Earthquakes in this belt are concentrated along major active reverse faults. Several great earthquakes have caused tremendous damage and loss of life. For example, the 


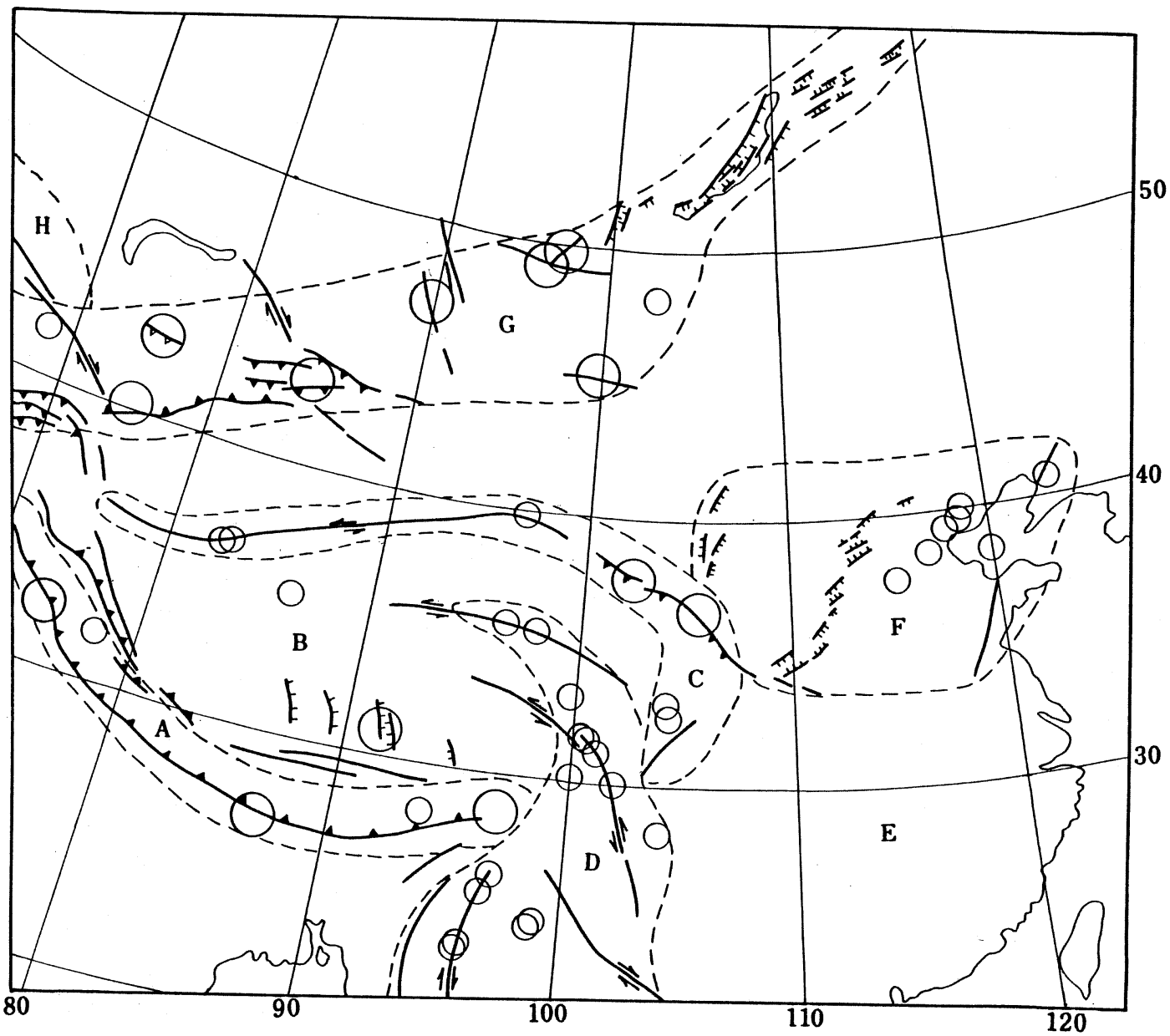

Fig. 2. Simplified active tectonic map of Continental Asia. Large circles represent epicenters of earthquakes of magnitude $\geq 8$. Small circles are epicenters of earthquakes of magnitudes between 7.0 and 7.9. Thick lines with solid triangles are active reverse and thrust faults; thick lines with ticks are active normal faults; thick lines with arrows are active strike-slip faults; other thick lines are other active faults. A, B, C, $\mathrm{D}, \mathrm{E}, \mathrm{F}, \mathrm{G}$, and $\mathrm{H}$ represent seismic belts or seismic regions of Himalaya, Tibetan Plateau, northern, and eastern margin of the Tibetan Plateau, Yunnan - Sichuan - Burma, Southern China, Northern China, Tianshan - Mongolia - Baikal, and Turan discussed in the text respectively.

1920 Haiyuan earthquake caused 200000 deaths and destroyed thousands of towns and villages (Zhang et al., 1987). This earthquake had a surface-wave magnitude of 8.6 and formed about $300 \mathrm{~km}$ of surface ruturing (Zhang et al., 1987).
Yunnan - Sichun - Burma region. This region is tectonically characterized by major strike-slip faults, since the penetration of India into Eurasia has already passed this region, and continuing penetration has resulted in a predominantly strike-slip environment. The 


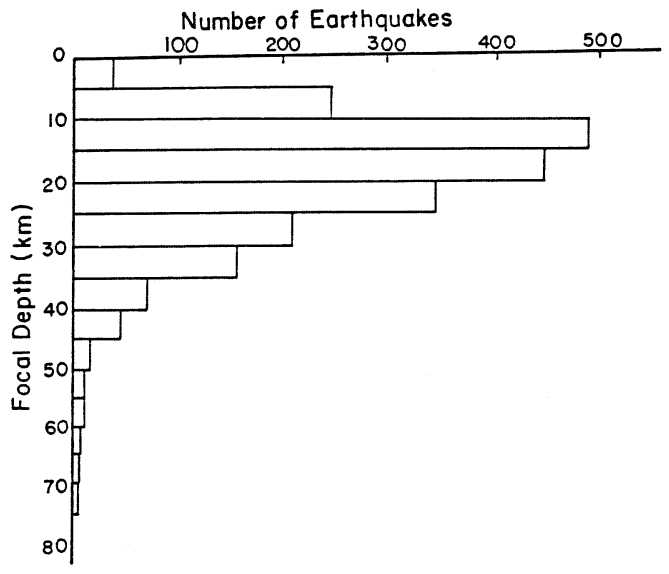

Fig. 3. Depth distribution of earthquakes (Ms>3) occurred in China between 1970 and 1985.

large earthquakes are mainly controlled by these strike-slip faults. Sixteen earthquakes of magnitude $>7$ have occurred in the Yunnan - Sichun - Burma region since the beginning of this century.

South China region. This region is characterized by relatively low seismicity compared to other seismic regions in China. Three earthquakes of magnitude $>7$ and one of magnitude $>8$ have occurred in this region during the past 1300 years. Since this region is densely populated and economically developed, earthquakes of magnitude 6 or larger could cause considerable damage.

North China region. This is a region of high seismic hazard. Strike-slip and normal faults are the predominant active structures in the North China region, which imply a large component of extension. The extension is probably caused, in part, by southeastward extrusion of Southeastern Asia with respect to Eurasia (Tapponnier and Molnar, 1977; Peltzer et al., 1988). There have been 6 earthquakes of $M>8$ and 16 earthquakes of $M>7$ in this region during the past 2000 years. Major earthquakes generally occur along major active faults that bound large basins. Fault-plane solutions of earthquakes are commonly strikeslip with normal dip-slip component. Although recurrence intervals along an individual fault are relatively long (usually in the range of several thousand years), the composite recurrence interval for the whole region is in the order of a few decades. The region is densely populated, and is the cultural and economic center of China. Every earthquake of magnitude $\geq 6$ has the potential for causing serious loss of life and economic damage. The 1976 Tangshan earthquake is a tragic example of the nature of seismic hazard in this region.

Tianshan - Mongolia - Baikal belt. This seismic belt is situated in the interior of Continental Asia. Late Quaternary deformation in the Tianshan Mountain is dominated by reverse faulting and crustal shortening and associated conjugate strike-slip faulting north of the Tianshan. The structural convergence in Tianshan is also attributed to India's penetration into Eurasia (Nelson et al., 1987). Neotectonics in Mongolia is characterized by strikeslip with thrust dip-slip component. The 1955 Gobi Altai $(\mathrm{M}=8)$ was associated with $8 \mathrm{~m}$ left-lateral displacement and about $5 \mathrm{~m}$ vertical offset (Tapponnier and Molnar, 1979). Lake Baikal is tectonically an intracontinental rift system which is predominated by normal faulting and crustal extension. There have been nine earthquakes of $M \geq 8$ and 22 earthquakes of $M \geq 7$ in the Tianshan - Mongolia - Lake Baikal seismic belt. Fault plane solution of earthquakes shows east-trending reverse faulting in the Tianshan, strike-slip faulting in Mongolia, and normal faulting in Baikal, which are consistent with results of late Quaternary deformation in this belt (Chen and Molnar, 1977; Tapponnier and Molnar, 1979; Molnar and Deng, 1984; Nelson et al., 1987).

Turan region. The Turan seismic region is located north of the Tianshan Mountain in Central Asia. The predominant structures in this regions are right-lateral strike-slip faults. The region is tectonically a transition area from active mountain building zone to the stable Russian platform. Seismicity in this region 
is medium. Two earthquakes of $M>7$ have been documented.

Distribution of earthquakes in Continental Asia is intimately tied with patterns of regional late Quaternary deformation. The tectonically active regions, such as the Yunnan $-\mathrm{Si}$ chun - Burma and the northern and eastern margin of the Tibetan Plateau, are regions with a high level of seismicity. The Turan and South China region, which tectonically are less active, coincide with a relatively low level of seismicity. Fault plane solutions of earthquakes in a seismic region show the same style of deformation as indicated by active tectonics of that respective region. Occurrence and mechanism of earthquakes are indicators of the style of contemporary deformation of a region.

\subsection{Temporal and spatial clustering of continental earthquakes}

On the basis of studies of active faults in the Basin and Range province of the United States, Wallace (1984) suggested a long-term pattern of temporal clustering behavior for major surface rupturing earthquakes $(M \geq$ 6.5) along an individual fault zone or a seis- mic region. The recognition of a temporal clustering pattern implies that displacement on fault occurs in a pulse of activity for a limited period in localized belts or subprovinces, while other areas remain relatively quiet in seismicity. After a pulse of major activity in one belt or area, activity shifts to another belt or area in the same tectonic province in some unknown sequence, but does not return to the first belt or area for long time (Wallance, 1984).

The modern seismicity in Continental Asia also shows apparent periodicity (temporal clustering); that is, the occurrence of strong earthquakes in a seismic region clustered in a period of time which is followed by a period of seismic quiescence. Analysis of historical earthquakes in China reveals this kind of pattern, with earthquake sequences having approximate return times of 300 years (McGuire, 1979; Ma Zongjin, 1984).

Several episodes of seismic activity can be further recognized within a given period of seismic activity (Ma Zongjin, 1984).

Earthquakes $(\mathrm{Ms} \geq 6.0)$ in Continental China since the beginning of this century clearly reveal the pattern of clustering/quiescence as showing by seismic energy release distribution as a function of time (fig. 4).

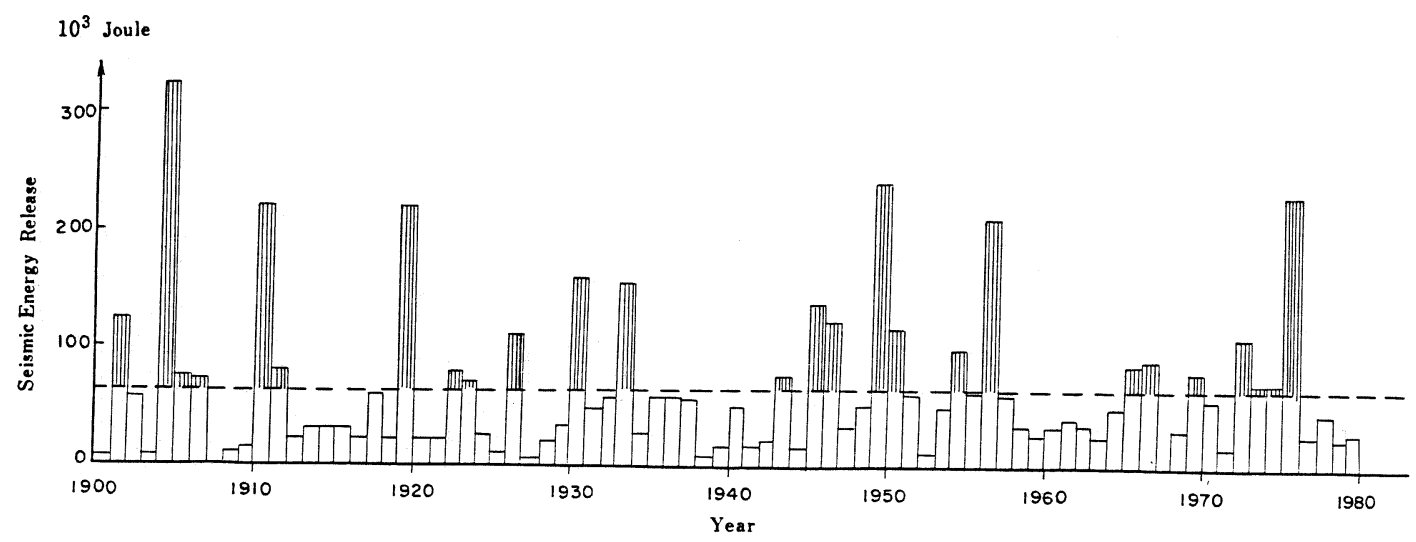

Fig. 4. Distribution of annual seismic energy release as a function of time from 1900 to 1980. The dashed line represents the normal annual seismic energy release. The shadowed bars above the dashed line are the annual seismic energy release in excess of the normal annual seismic energy release. Four episodes of seismic activity can be identified: 

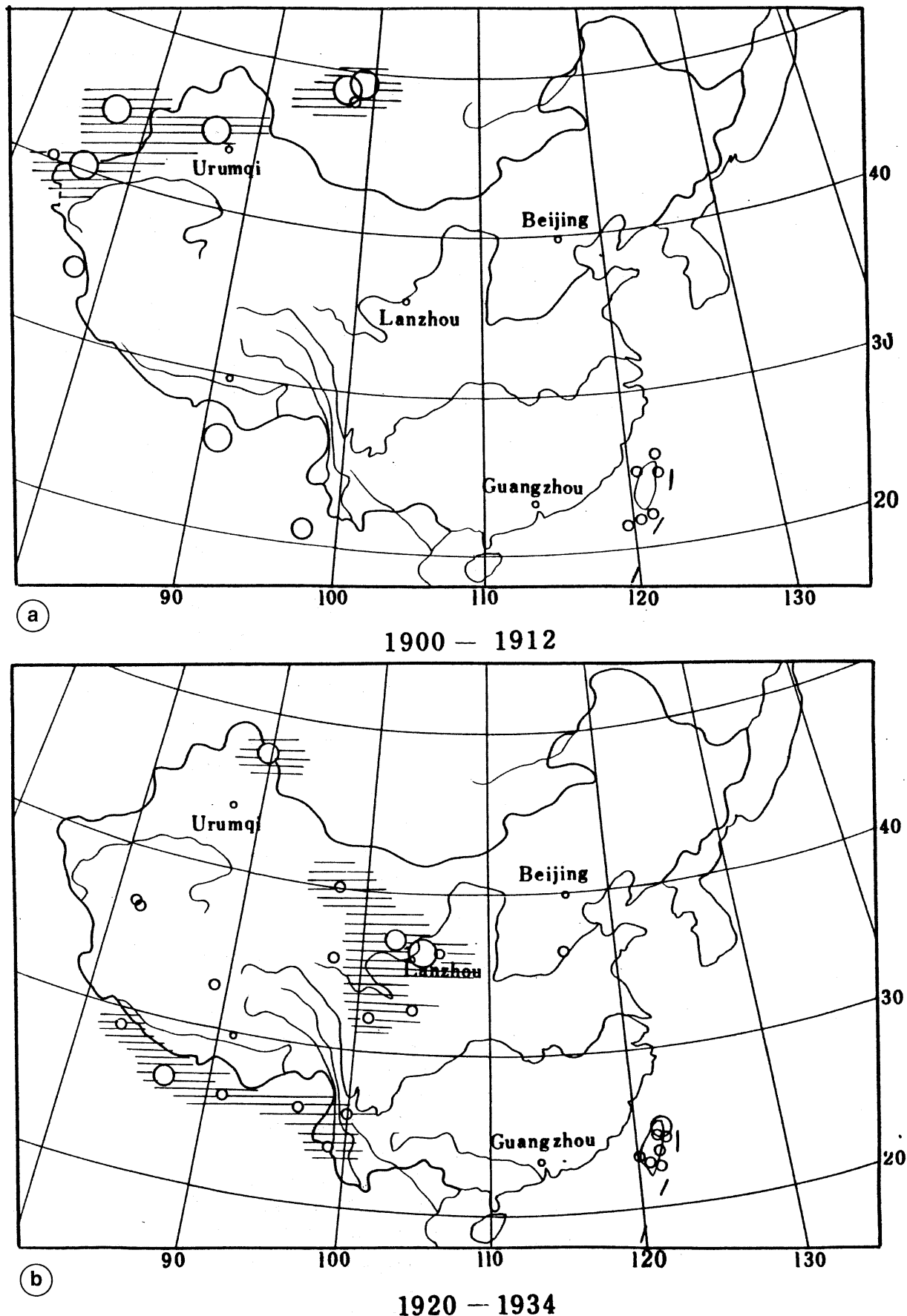

Fig. 5a) and b). Spatial distribution of earthquakes during the four episodes of seismic activity in China. The shadowed areas are the regions of major earthquakes during each episode of seismic activity. a) Shows the first episode from 1897 to 1912 ; b) shows the second episode from 1920 to 1934 . 


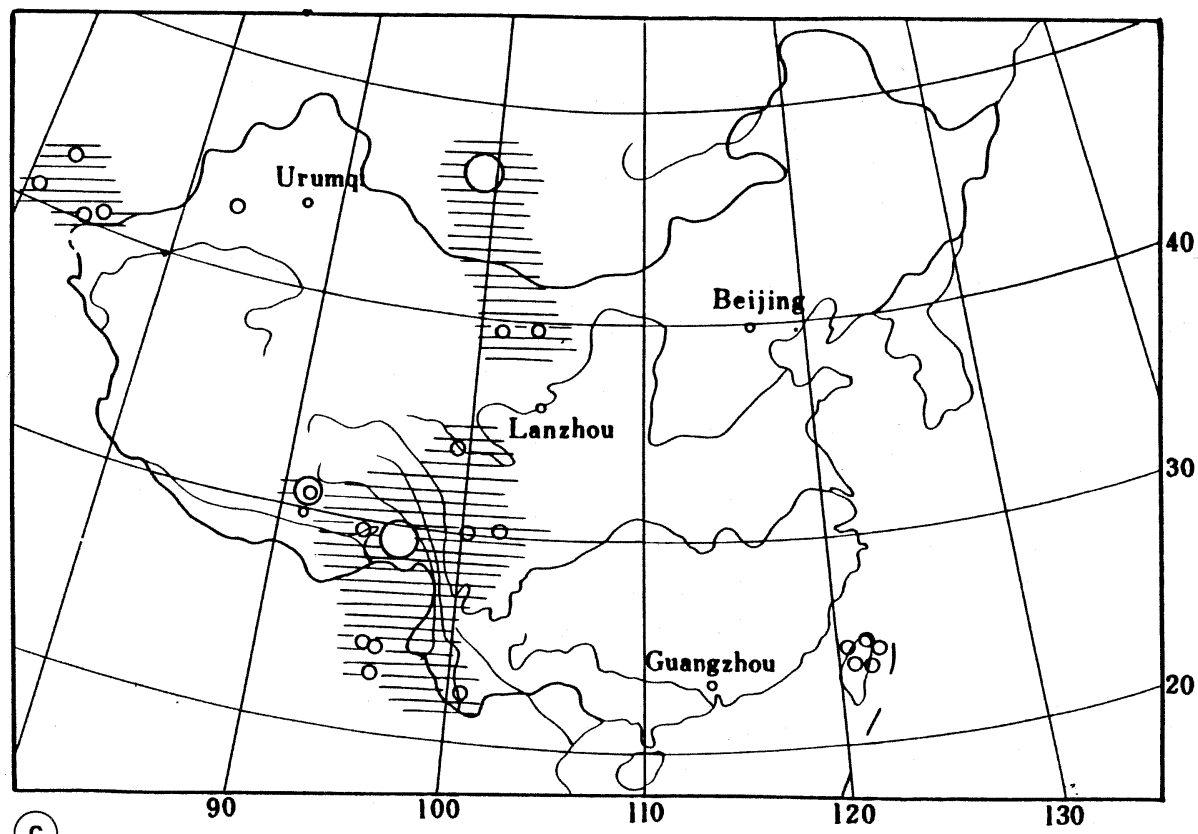

(c)

$1944-1957$

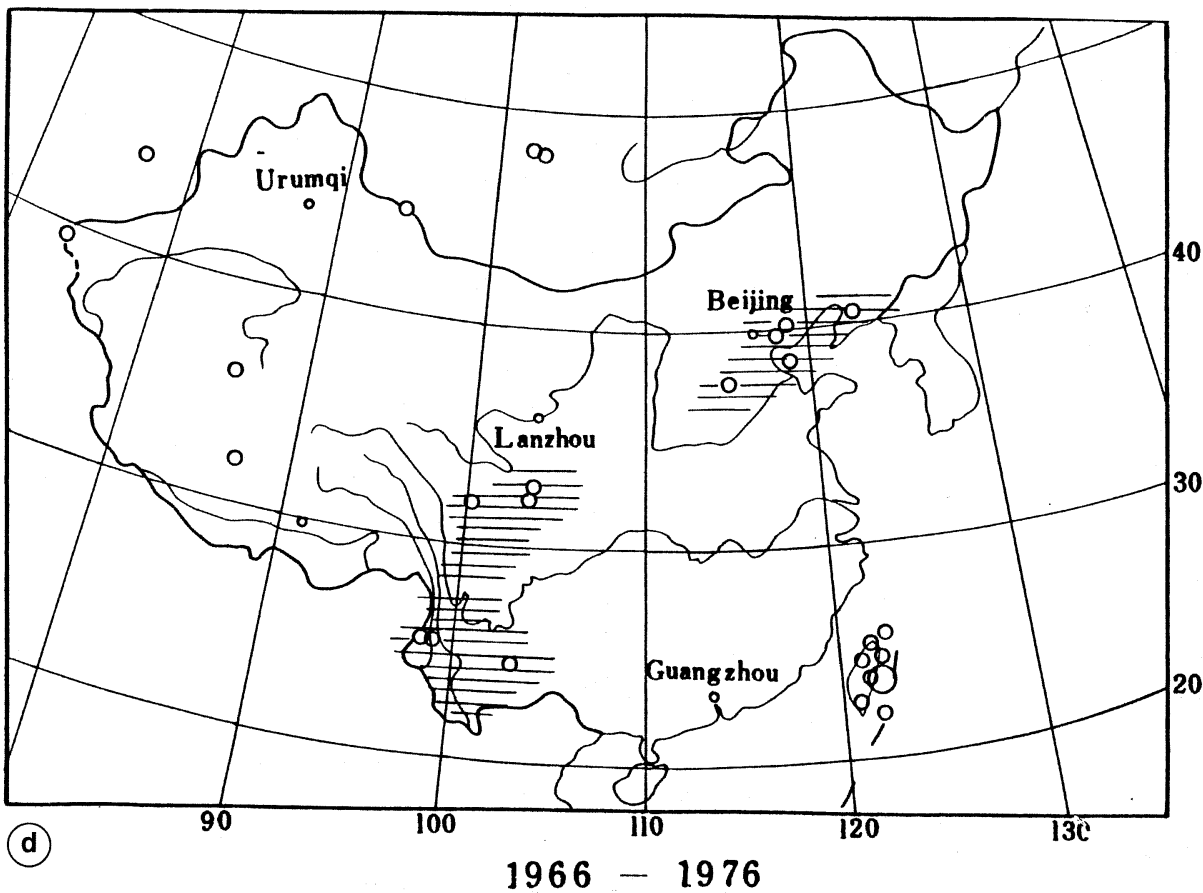

Fig. 5c) and d). Spatial distribution of earthquakes during the four episodes of seismic activity in China. The shadowed areas are the regions of major earthquakes during each episode of seismic activity. c) Shows the third episode from 1944 to 1957; d) shows the last episode from 1966 to 1976. 
The normal annual seismic energy release is defined as the average annual release over this century. The time episodes when the annual release of seismic energy successively exceeds the normal annual release are recognized as active episodes of seismicity. There have been 4 active episodes of seismicity in Continental China since the beginning of this century (fig. 4). These episodes occurred from 1897 to 1912,1920 to 1934,1944 to 1957,1966 to 1976 with intervals that persist for an average of 13 years. Several earthquakes of $M \geq$ 8 occur in each episode of activity.

Great earthquakes in an episode of seismicity mainly concentrate in one or two seismic belts or regions. In the succeeding seismic episode, earthquakes primarily occur in another (different) seismic belt and region. This pattern and behavior is similar to the longterm tectonic activity that Wallace (1984, 1987) recognized in the Basin and Range province.

Great earthquakes in the first recorded active episode of seismicity in China mainly occurred in Central Asia along the seismic belts of Pamier, Tianshan, and Mongolia (fig. 5a). In the second seismic episode, earthquakes occurred along the northern and eastern margin of the Tibetan Plateau seismic belt and along the Himalaya seismic belt (fig. 5b). Earthquakes in the third episode of activity were distributed in the seismic region of Southern and Eastern Tibet, and several large earthquakes also occurred in the Pamier and Mongolia seismic regions (fig. 5c). In the most recent seismic episode, the North China seismic region was the primary target for occurence of large earthquakes - the last disastrous earthquake in this episode was the 1976 Tangshan earthquake (fig. 5d).

The 1985 Wuqia earthquake $(\mathrm{Ms}=7.4)$ in the Tianshan seismic belt probably marks the onset of the fifth, and current, active episode of seismicity. If the duration of past seismic episodes is an indicator, the current episode might persist until 1995 or 2000, and we would anticipate one or more great earthquakes in this time period.

\section{Data bases for seismic hazard assessment}

Seismic hazard assessment has been a primary target of seismic hazard reduction activities in China during the past few decades. In 1970, the State Seismological Bureau (SSB) was established to organize nation-wide studies with a goal of reducing seismic hazards. Work conducted by SSB personnel includes earthquake monitoring and prediction, collecting earthquake data from various historical documents, coordinating national seismotectonic studies, conducting seismic intensity investigations, and compiling various maps for seismic hazard assessment including national seismic zonation maps.

It is well known that China has a rich history of earthquake recording. The earliest documented pre-instrumental event is the 1831 B.C. Tianshan earthquake. A relatively complete documentation of earthquakes in China began probably after 1300 A.D. during the Ming Dynasty (1368-1644). At this time most counties started to record historical events, including major earthquakes, and the documented events are relatively credible since this time. A total number of 757 historical earthquakes have been collected from various historical chronicles and the maximum modified Mercalli intensities (between VI and XII) have been assigned to the events on the basis of damage reports. Magnitude of these pre-instrumental events were estimated from the intensities using an empirical relation derived from instrumentally recorded earthquakes that occurred during the 20th century. Although the location and magnitude of these events contain large uncertainty, they nevertheless depict the general pattern of seismicity in China during that time period.

In 1966, China began to set up a modern national network of seismic stations. At the present time there are 727 seismic stations that are capable of monitoring $\mathrm{M}>2$ earthquakes in China and its vicinity. China published a national earthquake catalogue in 1983 (Gu, 1983). Since that time, a data base of historical and instrumental seismicity has been assembled. This data base is now available for 
assessing seismic hazard in Continental Asia and has been used in the new national seismic zonation map of China.

Although there are some strong ground motion records available in China, they are not enough for assessing seismic hazard. However, China has abundant seismic intensity data from investigantions of historical earthquakes. These intensity data can therefore be used to establish empirical relations for seismic attenuation of intensity with distance.

The occurrences of earthquakes in Continental Asia are mostly controlled by active faults. Considerable progress in active fault studies has been made in Continental Asia during the past two decades, including studies of late Quaternary slip rate, paleoseismicity, and fault segmentation that can be directly used in assessing seismic hazard. China has started a project to systematically map major active faults across the nation, and the data base of active faults will soon be assembled to provide significant geological and seismological input for making seismic hazard assessments.

\section{Current status in national seismic zonation}

Seismic zonation is a fundamental step toward reduction of seismic hazards. It is the basis for introducing low-cost earthquake-resistant building design and construction. The work of national seismic zonation conducted in China and the former USSR can be traced to early 1950's. The early work was mainly guided by two important principles proposed by the Russian seismologist Gorshkov: 1) that earthquakes of similar magnitude will recur where they have been previously and 2) regions of similar tectonic structure would be subject to similar seismic potential. Both China and the former USSR had compiled their first national seismic zonation map in the 1950's early based on these two principles. In 1977, China finished a new national seismic zonation map based on available seismic and seismotectonic data, and the predicted maximum seismic intensity for the time period of one hundred years (State Seismological $\mathrm{Bu}$ reau, 1981). This map has been used to develop a new national building code for China. In 1978, the former USSR published a second edition of its national seismic zonation map. This map depicts probability of expected maximum seismic intensity. The return time of expected maximum seismic intensity is divided into three categories: «once every hundred years», «once every thousand years», and «once every ten thousand years». This map has been used in national building code revisions for Russia and other former USSR republics.

China has recently finished its newest (third) national seismic zonation map, which represents major advances in seismic hazard assessment for China (State Seismological Bureau, 1992). The new national seismic zonation map was compiled at a scale of 1:4000000. The probabilistic approach of seismic hazard analysis, which was initiated by Cornell (1968), is applied instead of the deterministic approach utilized in the previous two versions. The map shows intensities with exceedence probability of $10 \%$ under average site conditions for a period of 50 years. The flow chart shown in fig. 6 indicates the method and procedure in compiling this map. Some of the rationales and techniques used to formulate the map are briefly elucidated in the following sections.

\subsection{Seismic source zone delineation}

Delineation of seismic source zones is a fundamental step in probabilistic earthquake hazard analysis. Seismic source zones are defined as areas that share common seismological, tectonic, and geological attributes under the assumption that these areas also share seismotectonic origins of seismicity that can be described by a unique magnitude-frequency relation (Thenhaus, 1986). This definition implies that seismicity in a seismic source zone is uniformly distributed throughout the zone and future earthquakes may occur everywhere in the zone. Observations of modern patterns of seismicity and paleoseismology studies, 


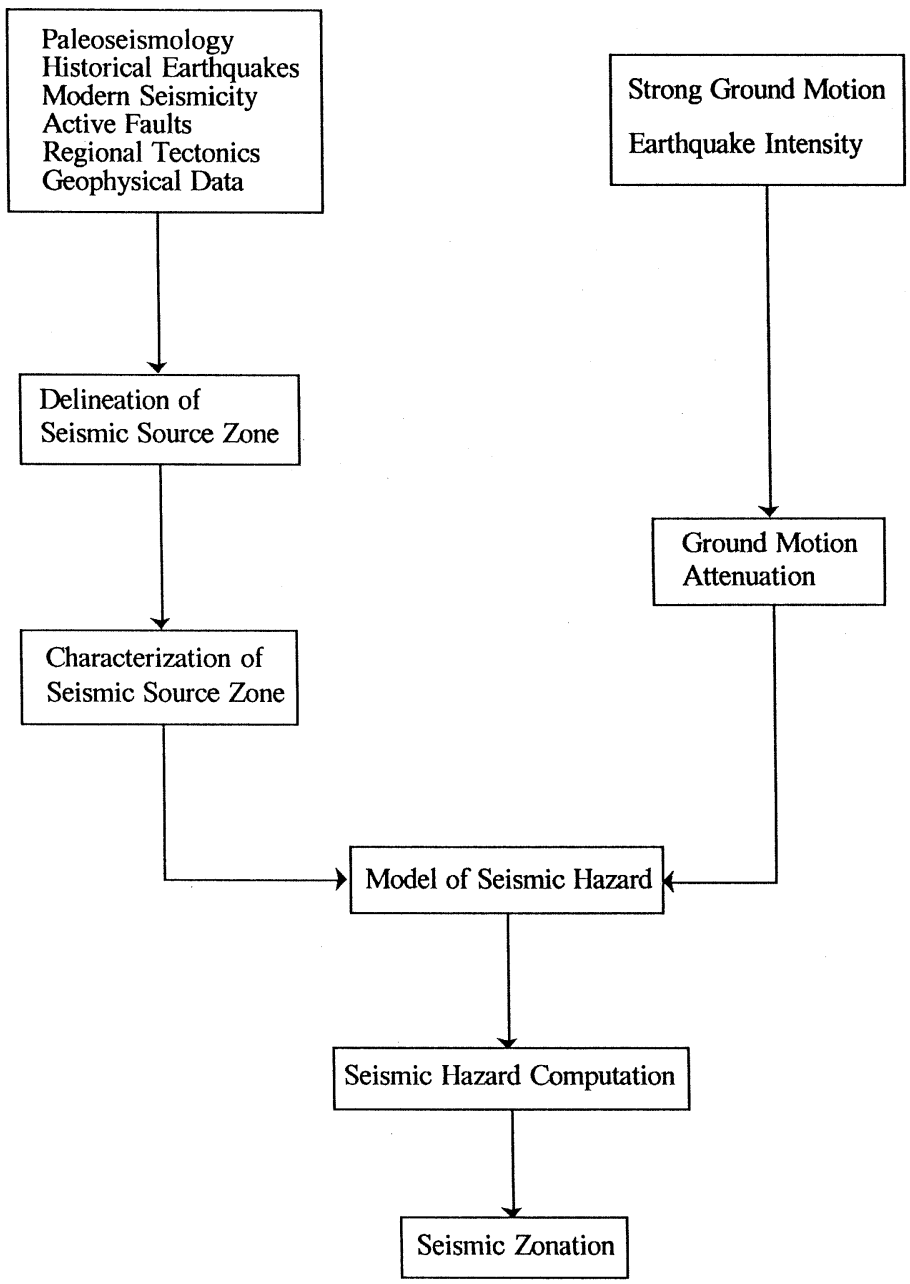

Fig. 6. Flow chart showing methods and procedures used in national seismic zonation of China (modified from State Seismological Bureau, 1992).

however, reveal irregular pattern of earthquake distribution in both time and space (e.g. Sykes, 1971; McGuire, 1979, 1981; Ma Zongjin et al., 1984; Wallace 1984, 1987). The previously described nature of seismic hazard in Continental Asia also shows deviation from the premise of the seismic source zone. Therefore, to realistically assess seismic hazard, the temporal and spatial variations in seismic potential ought to be incorporated in the delineation of seismic source zones.
In the conventional method of probabilistic seismic risk analysis (Cornell, 1968) the parameters of earthquake activity in a seismic source zone are determined by the statistics of its historical seismicity. This statistical approach precludes the seismic source zone from being delineated in enough detail to depict spatial irregularity of earthquake distribution because the earthquake catalogue would be inadequate for statistical analysis and the rate of earthquake activity would not represent the fu- 
ture earthquake potential. Also, if the seismic source is too large, the irregularities of earthquake potential would be averaged out and the probability of earthqhake recurrence would be diminished. To reconcile this contradiction and to reduce uncertainty in delineation of seismic source zones, Liu (1987) suggested a two-level delineation of seismic source zones that has been used in the new national seismic zonation of China.

The first level of seismic source zone delineation is a seismic belt (or seismic region), which is shown by «A» in fig. 7. The size of a seismic belt is large enough to encompass adequate earthquake data for statistical analysis. Although the seismic belt may consist of several sub-seismic sources of different strength and behavior, the rate of earthquake activity is a constant that represents average earthquake potential over the entire belt in the future period of interest. The Shanxi graben seismic belt in China (fig. 8), and the Central
Nevada - Eastern California seismic belt in USA (Wallace, 1984; Zhang et al., 1991) are typical examples of this level of seismic source zone. They consist of several surface ruptures associated with historical earthquakes and segments of active faults, which share common tectonic origins and seismic attributes. The purpose for delineating this level seismic source is to ensure enough historical earthquakes for statistical treatment and to obtain reliable parameters of earthquake activity characterizing future average seismic potential.

The second level of seismic source zone is termed a seismic source, which is illustrated by $« B »$ in fig. 7 . Delineation of seismic sources is, in fact, a further subdivision of firstlevel seismic belt based on geological, geophysical, and seismological information of the belt. Each seismic source within a seismic belt may differ in terms of geometry, maximum earthquake magnitude and recurrence interval, and rate of earthquake activity. This level of

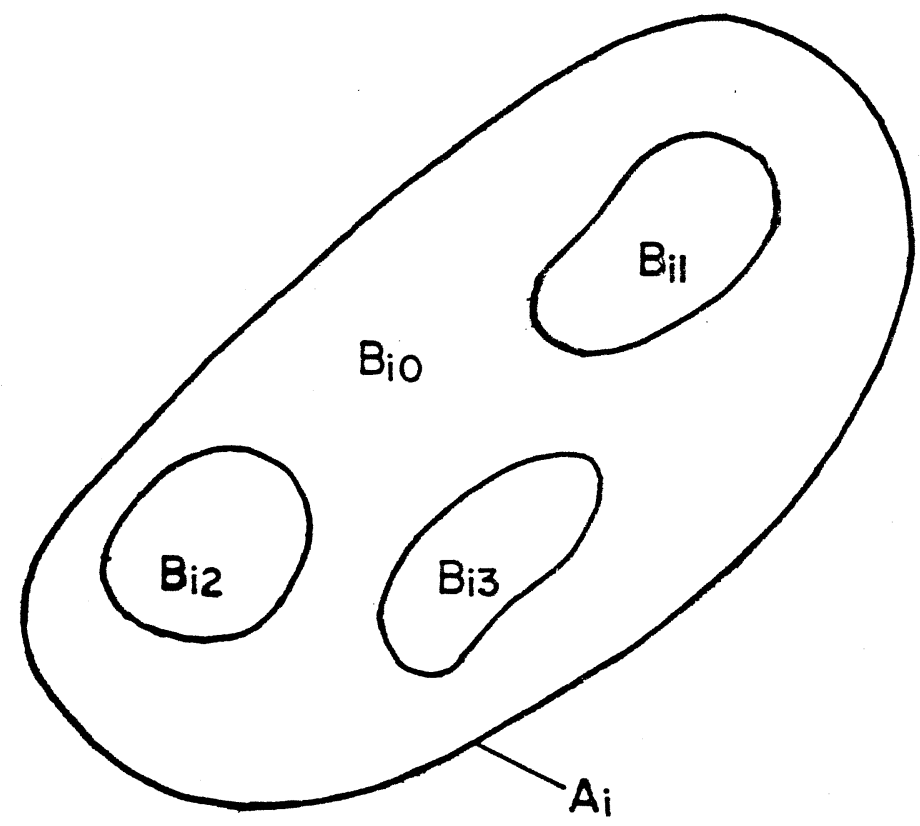

$R_{i j}=\frac{W_{i j} B_{i j}}{\sum_{j} W_{i j} B_{i j}} R_{i}$

$R_{i}=\sum_{j} R_{i j}$

Fig. 7. Diagram showing the two level delineation of seismic source zones used in national seismic zonation map of China (modified from Liu Huixiang, 1987). 


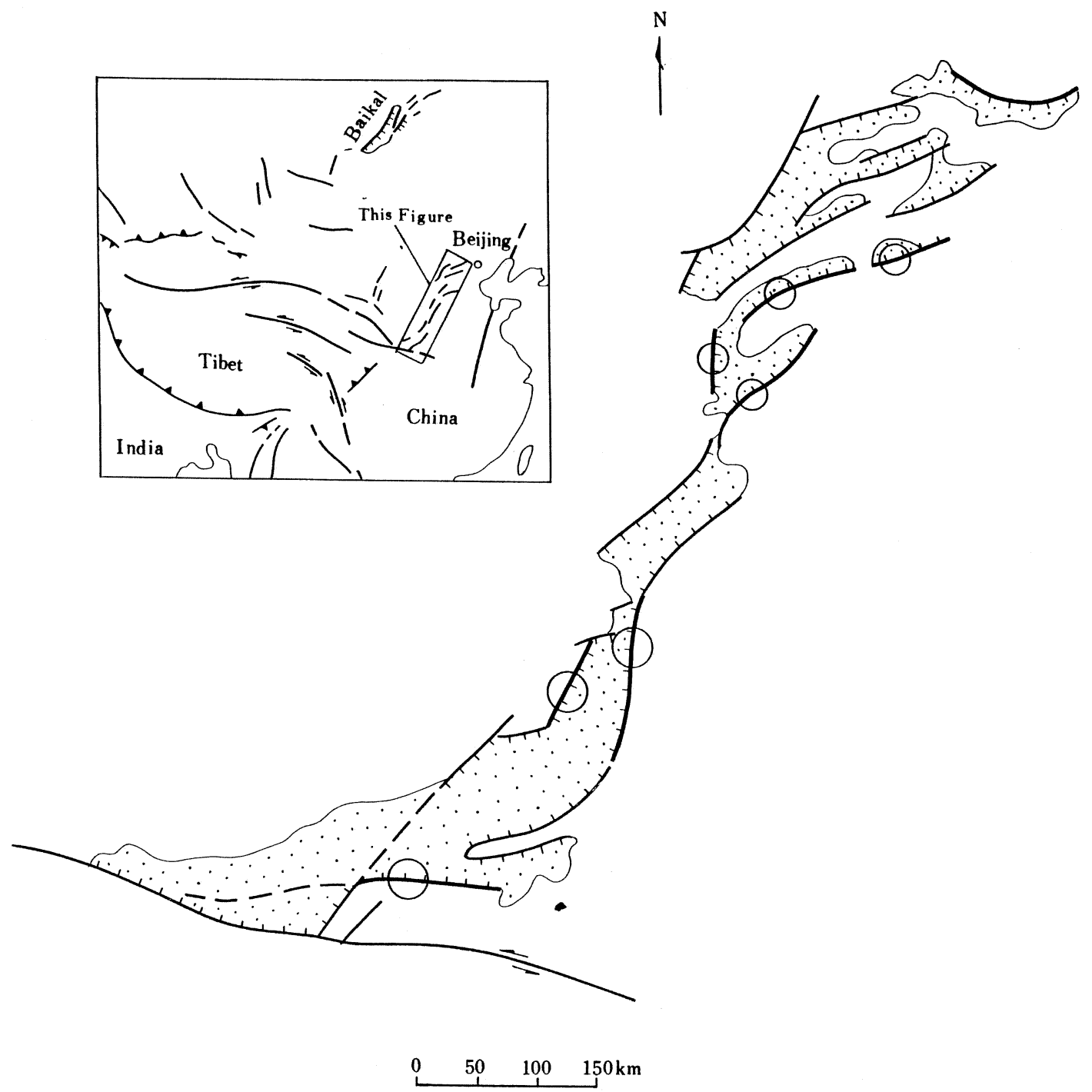

Fig. 8. Simplified map of active faults along the Shanxi graben system of Northern China. Dotted areas are Quaternary basins. The very thick lines with ticks are surface ruptures associated with historical earthquakes; the medium thick lines are major active faults; the thin lines are sedimentary boundaries of basins. Large circles are epicenters of earthquakes of magnitude $\geq 8$; small circles are epicenters of earthquakes between 7.0 and 7.9 . 
delineation illustrates spacial irregularity of earthquake distribution so that weighting factors could be assigned to each seismic source in distributing the total probability of earthquake recurrence over the first level of seismic source zone. Using the Shanxi graben system and the Central Nevada and Eastern California seismic belt as examples, the segments of active faults, no matter whether they ruptured in the historical time or not, are seismic sources of the belt. Obviously, the total rate of earthquake activity of the seismic belt is not uniformly distributed in each seismic source (each segment) of the belt although the annual rate of earthquake activity is a constant for the whole graben system or the whole seismic belt. In other words, the seismic potential in different segments of either the Shanxi graben system or the Central Nevada and Eastern California seismic belt is different during the next 50 or 100 years in the future. The segments that have historically ruptured are unlikely to rupture again in the next 50 or 100 years, and segments that have not yet ruptured historically are the sites with high potential for the near future earthquakes.

\subsection{Seismic source zone characterization}

The new national seismic zonation map of China (State Seismological Bureau, 1992) uses the following parameters to characterize seismic source zones and seismic sources:

1) effective magnitude, the minimum magnitude of earthquake that may cause strong ground motion at a site;

2) maximum earthquake magnitude, determined by maximum magnitude of historical earthquake, maximum magnitude of paleoearthquake if data exist, and seismotectonic analogies;

3) b-value of Gutenberg-Richter relations, obtained from statistics of earthquakes in a seismic source belt;

4) rate of earthquake activity, annual number of earthquakes of magnitude larger than the effective magnitude that occurred in the seismic belt;
5) spatial and temporal distribution function of earthquake activity, carrying information on temporal and spatial variation of earthquakes in the seismic belt.

The rate of earthquake activity is a very important parameter in seismic hazard analysis. The idea of characterizing the temporal and spatial irregularity is to let the rate of earthquake activity in each seismic zone (area «A» in fig. 7) remain a constant, but irregularly redistribute into different seismic sources (area $« \mathrm{~B} » \mathrm{~s}$ in fig. 7) within the belt using a weighting function (Liu, 1988). In practice, a two-step determination of earthquake activity parameters is employed. The first step is to determine effective earthquake magnitude, maximum earthquake magnitude, b-value, and annual rate of earthquake activity for the whole seismic belt. The second step is to determine the rate of earthquake activity for each of the seismic sources by means of the distribution function (weighting function) of earthquake activity. Figure 7 illustrates the concept of the two-step characterization of seismic sources.

The critical question is how to determine the weighting function for each seismic source within a seismic belt. To characterize the spatial irregularity the following factors are considered in each seismic source: recency of the last earthquake, lithological and structural property, degree of tectonic activity, reliability of seismic source obtained from pattern recognition study, and size of seismic source. A weighting coefficient is assigned to each seismic source based on evaluation of the above factors.

Temporal variation of seismicity is characterized by periodicity of seismic activity in a seismic province. Four phases of activity can be recognized from a periodicity of seismicity based on analysis of Chinese earthquake catalogue up to 1989 (Liu, 1987), namely, the phase of energy accumulation (marked by the quiescence in activity); the phase of increasing energy release (marked by moderate earthquakes); the phase of intense energy release (marked by major earthquake events); and the phase of complete release (marked by gradual 
decreasing in activity). By observing the present phase in the seismic periodicity, it is possible to make a choice of the seismic parameter for the future time span of interest. For example, if the activity of a seismic zone in the future time span of interest is going to be the phase of intense energy release, the rate of earthquake activity for that future time span should be larger than that obtained from statistics of earthquakes occurred in previous phases. In practice, this is achieved by assigning a weight coefficient to increase or decrease the rate of earthquake activity of a seismic source zone.

\subsection{Ground motion attenuation and seismic recurrence model}

The new national seismic zonation map of China is mapped in intensity grade rather than physical parameters, such as peak ground acceleration and peak ground velocity. The reasons for doing so follow Liu Huixiang (1987). The state-of-the-art of seismic hazard assessment in China remains at a low level, it is impossible to give the strong ground motion in crisp values of the physical parameters. Since it is not feasible to install strong ground motion instruments all over China in the near future, evaluation of the severity of earthquakes will still depend on a descriptive intensity scale (Modified Mercalli). China has a wealth of descriptive earthquake data but only a handful of strong ground motion records. For engineering use, intensity grade is more flexible than certain physical parameters because the intensity grade could be correlated to any physical parameter, and earthquake countermeasures are much more feasible to formulate according to intensity grade than to be physical parameters (Liu, 1987).

The general form of seismic intensity attenuation relation used world-wide is

$$
\mathrm{I}=\mathrm{a}_{0}+\mathrm{a}_{1} \mathrm{M}-\mathrm{a}_{2} \ln \left(\mathrm{R}+\mathrm{R}_{0}\right)
$$

where the coefficients $a_{0}, a_{1}, a_{2}, R_{0}$ are obtained from regression of isoseismal values for historical earthquakes, I is seismic intensity,
$\mathrm{M}$ is earthquake magnitude, and $\mathrm{R}$ is epicentral distance in $\mathrm{km}$. Based on characteristics of earthquakes in China, ellipsoid shape is used to model attenuation of intensity with distance. Both the long- and short-axes are modeled respectively. To keep the variables used in the regression independent of each other, the magnitude of earthquakes was determined by instrumental data, and their isoseismal (or intensity) values were observed directly from field investigation. Since the eastern and western parts of China differ in geology, seismology, and active tectonics, different attenuation relationships are used in calculating seismic hazards.

Eastern China:

Long Axis

$\mathrm{I}=6.046+1.480 \mathrm{Ms}-2.081 \ln (\mathrm{R}+25) ; \mathrm{S}=0.49$

Short Axis

$\mathrm{I}=2.617+1.435 \mathrm{Ms}-1.441 \ln (\mathrm{R}+7) ; \mathrm{S}=0.56$

Western China:

Long Axis

$\mathrm{I}=5.643+1.538 \mathrm{Ms}-2.109 \ln (\mathrm{R}+25) ; \mathrm{S}=0.64$

Short Axis

$\mathrm{I}=2.941+1.363 \mathrm{Ms}-1.494 \ln (\mathrm{R}+7) ; \mathrm{S}=0.61$

In the equations, Ms is surface-wave magnitude, and $\mathrm{S}$ is standard deviation.

On a worldwide basis, two kinds of models of earthquake recurrence are often used in the recent seismic hazard assessment: stationary Poisson model and other non-stationary models. The Poisson model represents a non-memory process, which implies that the occurrence of a future event is independent from the past event. This obviously deviates from our current understanding of processes of earthquake generation. However, the Poisson model is widely used in current seismic hazard assessment for its simplicity, which satisfies the availability of current data. Non-Poisson models, such as Markov, renewal (real time), and time-predictable, seem to be more realistic than the stationary model currently used. However, these non-stationary models require estimation of many constants and parameters that are currently either not known or for which the data base is too small to be estimat- 
ed with any confidence. Therefore, a stationary Poisson model was adopted in compiling the new national seismic zonation map of China.

\section{Problems and future directions}

The problems that prevent us from realistically assessing seismic hazards result from two sources: small data bases of quality seismic data and limited understanding of the process of earthquake generation. First, the history of earthquake recording around the globe is too short to represent the real behavior of seismicity either in an area or along a particular fault. Even though China has more than a two thousand year old history of earthquake documentation, most of the earthquake data are only general descriptions of the earthquake hazard and are far from complete. Recurrence intervals of continental earthquakes are generally from several thousand years to more than ten thousand years (Wallace, 1984). Thus, the time window for making statistical analysis of rates of seismicity is usually only a few decades, at best. It is very difficult to estimate confidence levels for statistical results based on such a small data base. Secondly, earthquakes comprise a very complex process of rupture. At present, our knowledge on the processes of earthquake generation is still in a young stage of development. The degree to which seismic hazard can be adequately assessed depends in part on our ability to correctly describe processes of earthquake generation and to realistically establish models of seismic hazard that incorporate such processes.

As mentioned above, a great deal of uncertainty is involved in each step of a seismic hazard analysis that is based primarily on earthquake frequency statistics obtained from historical catalogues of seismicity. The uncertainty in such analyses is particularly large when the historical record is too short to define secular rates of seismicity, which is the usual case. Probabilistic approaches rather than deterministic approaches, have been widely used to account for the uncertainties in the size, timing, location and attenuation of seismic events. However, we should all recognize that probabilistic models of nature do not in themselves increase our information, and that they at best help us organize our knowledge in a useful way (Cornell, 1986). Since it is not feasible to obtain enough additional earthquake data to increase our data base in the near future, we have to look for other ways to improve our ability in assessing seismic hazard. The following discussion centers on three of the issues that need improvement.

1) Incorporation of more geological and geophysical information. To some extend, historical records of seismicity are of minimal value for determining the recurrence interval between large events because of the short history of seismic recording and the uncertainty of earthquake location versus causative fault (Crone, 1987). Under the best circumstances in very active areas, such as China, the historical records are incomplete and subject to varying amounts of interpretation. Where earthquake recurrence is measured in tens of thousands of years, such as the Basin and Range province of the United States, the historical record is essentially useless (Crone, 1987). Geological records of Quaternary offset contain information on the recurrence of earthquakes through periods of time many orders longer than the average repeat time of large earthquakes on individual faults and orders of magnitude greater than periods covered by historical records. Observation such as these led a number of investigators to argue that geological information of fault slip rates may be used to reduce uncertainties associated with estimation of long-term seismicity, and in turn, seismic hazard (e.g., Allen, 1975; Anderson, 1979; Molnar, 1979; Youngs and Coppersmith, 1985; Wesnousky, 1986). The use of geological information in each procedure of assessing seismic hazard is illustrated in fig. 9.

The new tools of paleoseismology and concepts of fault segmentation in active fault studies are especially important in assessing seismic hazard (Crone, 1987; Schwartz, 1988). Paleoseismology is the study of the age, frequency, and size of prehistoric earthquakes 


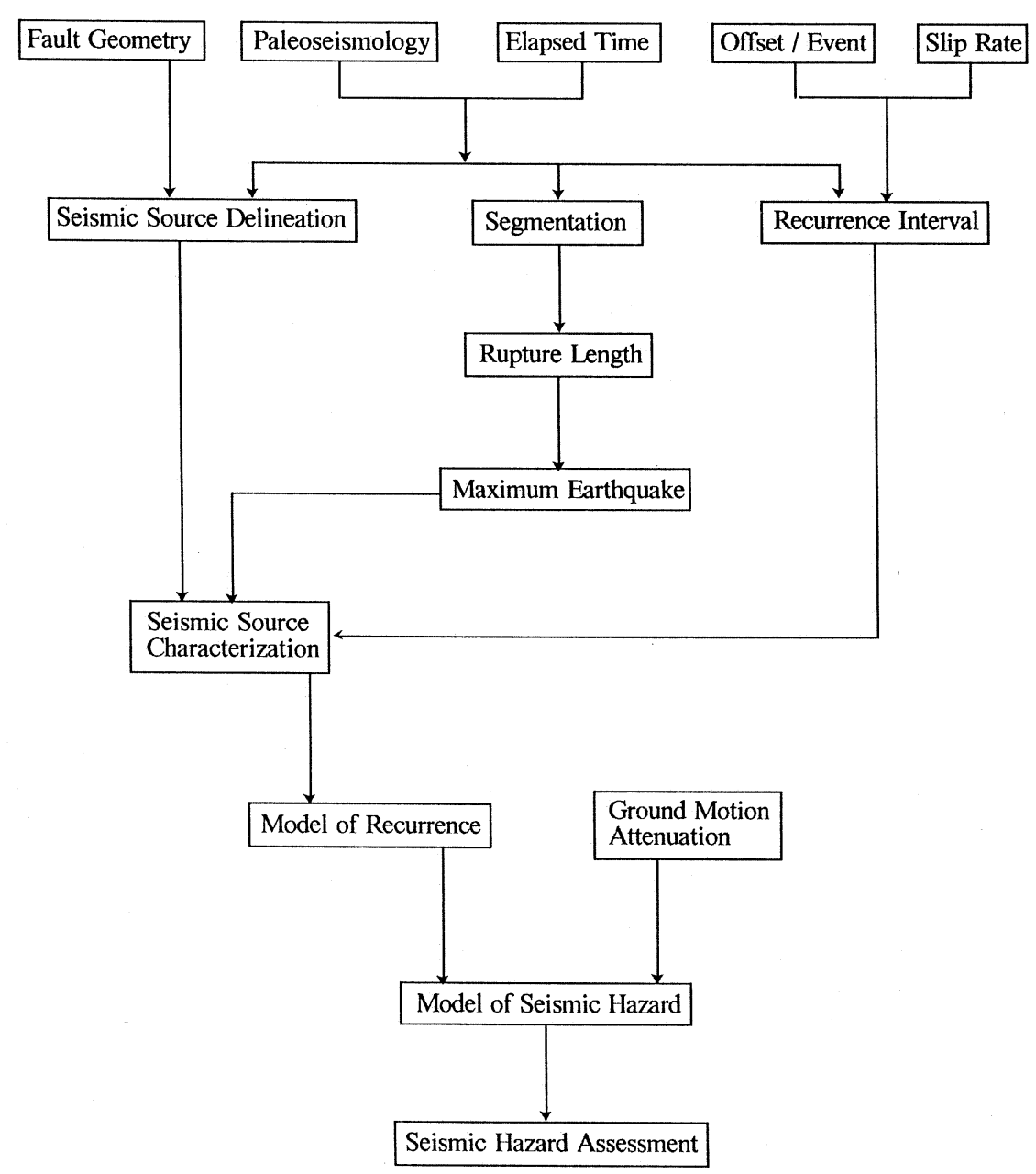

Fig. 9. Flow chart showing application of geological information in each procedure of seismic hazard assessment.

(Wallace, 1981). It provides a means to expand the limited view of earthquakes offered by the historical and instrumental record and helps us understand the long-term behavior of seismogenic faults (Wallace, 1981). Through studies of individual prehistorical seismic events, we hope to characterize the coseismic behavior of seismogenic faults, to identify variations in the spatial and temporal distribution of earthquakes, and to detect patterns of long- term and regional seismicity (Crone, 1987). The independent behavior of fault segments has important implications for seismic hazard evaluation. Segmentation models of active faults or a seismic belt, when well constrained, provide a physical basis for delineation of seismic sources ( $\ll \mathrm{B} » \mathrm{~s}$ in fig. 7$)$ within a seismic belt and for selection of rupture length used in the calculation of maximum earthquakes. Also, if a fault is segmented, the 
potential hazard posed by each segment may be different. For example, variability in segment length will mean variability in the size of maximum credible earthquake. Moreover, recognition of segments and of the difference in the behavior of each will be extremely important for long-term earthquake forecasting. Information on the difference in the elapsed time and the recurrence intervals for each segment can help assess where the next major event will most likely occur along a fault zone and to calculate the probability of occurrence for that event. This type of data would provide the basis for distributing the rate of earthquake activity among the seismic sources within a seismic belt through the use of weighting factors.

2) Improving seismic models to realistically describe the physics of earthquake generation process. Probabilistic seismic hazard assessment provides estimates of the probability of future earthquake occurrence through the use of earthquake hazard models with assumptions based on a physical and statistical understanding of the earthquake process. The Poisson process may not be compatible with the physical processes of earthquake generation in terms of strain accumulation and release, but it has been widely used for its simplicities. Other seismic models, which are believed to be more realistic than the Poisson model, have been available for many years, but have not had a major impact on seismic hazard assessment (Cornell, 1986; Schwartz, 1988) owing to a lack of robust data. The pressing need is therefore to develop more physical, mechanical, and practical models on the basis of available data to realistically describe the process of earthquake generation.

3) Using multiple approaches. «Approaches» are general ways of assessing seismic hazard. There are more than one set of data, more than one model, and more than one method that can be used in each step of seismic hazard assessment (delineation, characterization, modeling, and computation of seismic hazards). Since earthquake processes are not well understood at present, and there is no single technique that can be applied without uncertainty, multiple approaches result in more reliable estimates of seismic hazard than the application of any single approach. In this way a wide range of fault behavior information can be included in the analysis, and the resulting hazard estimates will be those that are substantiated by the available data (Coppersmith, 1982). Thus, the use of multiple approaches in each step of assessing seismic hazard are strongly encouraged.

\section{Conclusions}

Major earthquakes are widely distributed over Continental Asia and are intimately tied with style of late Quaternary regional deformation. Observations in the modern pattern of seismicity and paleoseismological studies reveal irregularity of earthquake distribution in both time and space. To realistically assess seismic hazard, the temporal and spatial variations in seismic potential ought to be incorporated in each step of seismic hazard assessment. The method of a two-level delineation and characterization of seismic source zones used in Chinese new national seismic zonation is one of the ways to treat the temporal and spatial clustering of the earthquakes. A great deal of uncertainty, however, is still involved in each step of a seismic hazard analysis owing to small data bases of quality seismic data and limited understanding of the process of earthquake generation. To increase our ability in assessing seismic hazard, we need to incorporate more geological and geophysical information, to improve seismic models to describe the physical process of earthquake generation, and to use multiple approaches in each step of seismic hazard assessment.

\section{Acknowledgements}

I am grateful to Ma Zongjin, Ye Hong, Wang Liangmu, Mao Fengying from Institute of Geology, State Seismological Bureau of China for their help during the preparation of this paper. I thank Lu Shoude from State 
Seismological Bureau of China for his encouragement and cooperation. I am greatly indebted to Michael Machette for his comments and editions. I also thank Peter Basham, Michael Berry, and Dominico Giardini for inviting me to write this paper.

\section{REFERENCES}

Allen, C.R. (1975): Geological criteria for evaluating seismicity, Bull. Seismol. Soc. Am., 86, 1041-1057.

ANDERson, J.G. (1979): Estimating the seismicity from geological structure for seismic risk studies, Bull. Seismol. Soc. Am., 69, 135-158.

ArmiJo, R., P. TApponnier, J.L. Mercier and T. HaN (1986): Quaternary extension in Southern Tibet: field observations and tectonic implications, $J$. Geophys. Res., 91, 13803-13872.

Chen, W.P. and P. Molnar (1977): Seismic moments of major earthquakes and the average rate of slip in Central Asia, J. Geophys. Res., 82, 2945-2969.

Chen, W.P. and P. Molnar (1983): Focal depths and fault plane solutions of earthquakes under the Tibetan Plateau, J. Geophys. Res., 88, 1180-1196.

COPPERsmith, K.J. (1982): Probabilistic evaluations of earthquake hazards, Calif. Divi. of Mines and Geol., Special Paper 62, 125-134.

CoRNELl, C.A. (1968): Engineering seismic risk analysis, Bull. Seismol. Soc. Am., 58, 1583-1606.

Cornell, C.A. (1986): Where do we go from here to increase the state of knowledge? A workshop on «Probabilistic Seismic Hazard Assessments», U.S. Geol. Surv. Open-File Report, 86-185, 19-24.

CRONE, A.J. (1987): Introduction to directions in paleoseismology, U.S. Geol. Surv. Open-File Report, 87673, $1-7$.

Feng HaO (1991): Characteristics of seismicity in China, Seismological Publishing House, An introduction to Lithospheric Dynamics of China, pp. 193-200.

Gu Gongxiu (1983): Earthquake Catalogue of China, Seismological Press.

LyON-CAEN, H. and P. Molnar (1985): Gravity anomalies, flexure of the Indian plate, and the structure, support and evolution of the Himalaya and Ganga Basin, Tectonics, 4, 513-538.

Liu, Huixiang (1987): On the seismic zoning map China, Proceedings of International Seminar on Seismic Zonation, pp. 35-42.

Ma Zonguin, Chen Zhangli, Zhu Yueqing, Wang LipING AND XUE FENG (1984): The basic characteristics of the continental earthquakes, A Collection of Paper of International Symposium on continental Seismicity and Earthquake Prediction, pp. 299-311.

Ma Zonguin, Fu ZhengXiang, Zhang Yingzhen, Wang Chengmin, Zhang Guomin and Liu Defu (1989): Earthquake Prediction: nine major earth- quakes in China, Seismological Press and SpringerVerlag.

McGuIRE, R.K. (1979): Adequacy of simple probability models for calculating felt-shaking hazard, using the Chinese earthquake catalogue, Bull. Seismol. Soc. Am., 69, 877-892.

MCGuire, R.K. and T.P. BARNhARD (1981): Effects of temporal variations in seismicity on seismic hazard, Bull. Seismol. Soc. Am., 71.

Molnar, P. (1979): Earthquake recurrence intervals and plate tectonics, Bull. Seismol. Soc. Am., 69, 115-133.

Molnar, P. and Q. Deng (1984): Faulting associated with large earthquakes and average rate of deformation in Central and Eastern Asia, J. Geophys. Res., 89, 6203-6227.

Molnar, P. and H. Lyon-CAEN (1989): Fault plane solutions of earthquakes and active tectonics of the Tibetan Plateau and its margins, Geophys. J. Int., 99, 123153.

Molnar, P. and P. TAPponnier (1975): Cenozoic tectonics of Asia: effects of a continental collision, Science, 189, 419-426.

Molnar, P. and P. TAPPONNIER (1978): Active tectonics of Tibet, J. Geophys. Res., 83, 5361-5374.

Nelson, M.R., R. MaCaffrey and P. Molnar (1987): Source parameters for 11 earthquakes in the Tian Shan, Central Asia, determined by P and SH waveform inversion, J. Geophys. Res., 92, 12629-12648.

Peltzer, G. and P. TAPponnier (1988): Formation and evolution of strike-slip faults, rifts, and basins during the India-Asia collision: an experiment approach, $J$. Geophys. Res., 93, 15085-15117.

SCHWARTZ, D.P. (1988): Geologic characterization of seismic sources moving into the 1990s. American Society of Civil Engineers, Geotechnical Special Publication, 20, 1-42.

State Seismological Bureau of China (1981): Report on national seismic zonation of China, Seismological Press (in press).

State Seismological Bureau of China (1992): The third edition of national seismic zonation map of China, Seismological Press (in press).

SYKES, L.R. (1971): Aftershoke zones of great earthquakes seismicity gaps, and earthquake prediction for Alaska and the Aleutians, J. Geophys. Res., 76, 8021-8041.

TAPPONNIER, P. and P. Molnar (1977): Active faulting and Cenozoic tectonics of China, J. Geophys. Res., 82, 2905-2930.

TAPPonnier, P. and P. Molnar (1979): Active faulting and Cenozoic tectonics of the Tien Shan, Mongolia, and Baikal region, J. Geophys. Res., 84, 3425-3459.

Trenhaus, P.C. (1986): Seismic source zones in probabilistic estimation of the earthquake ground motion hazard: a classification with key issues. A workshop on «Probabilistic Seismic Hazard Assessments», U.S. Geol. Surv. Open-File Report, 86-185, 53-71.

Wallace, R.E. (1981): Active faults, paleoseismology, and earthquake hazard in the Western United States, in Earthquake Prediction - an international review, 
edited by D.W. Simpson and P.G. Richards, Washington, D.C., American Geophysical Union, Maurice Ewing Series 4, 209-216.

Wallace, R.E. (1984): Patterns and timing of late Quaternary faulting in the Great Basin Province and relation to some regional tectonic features, J. Geophys. Res., 89, 5763-5769.

WALLACE, R.F. (1987): Grouping and migration of surface faulting and variation in slip rate on faults in the Great Basin Province, Bull. Seismol. Soc. Am., 77, 868-876.

WESNOUSKY, S.G. (1986): Earthquakes, quaternary faults, and seismic hazard in California, J. Geophys. Res., 91, 12587-12631.
Youngs, R.R. and K.J. CoPPERSMith (1985): Implications of fault slip rates and earthquake recurrence models to probabilistic seismic hazard estimates, Bull. Seismol. Soc. Am., 75, 939-964.

Zhang, W., D. Jiao, P. Zhang, P. Molnar, B.C. Burchfiel, Q. Deng, Y. WANG and F. Song (1987): Displacement along the Haiyuan fault associated with the great 1920 Haiyuan, China, earthquake, Bull. Seismol. Soc. Am., 77, 117-131.

Zhang, P., B.D. Slemmons and F. Mao (1991): Geometric pattern, rupture termination, and fault segmentation of the Dixie Valley - Pleasant Valley active normal fault system, Nevada, U.S.A., J. Struct. Geol., 13, 165-176. 